\title{
Tracking lodide and Bromide Ion Segregation in Mixed Halide Lead Perovskites during Photoirradiation
}

\author{
Seog Joon Yoon, ${ }^{1,2}$ Sergiu Draguta, ${ }^{2}$ Joseph S. Manser, ${ }^{1,3}$ Onise Sharia, ${ }^{3}$ \\ William F. Schneider, ${ }^{2,3}$ Masaru Kuno, ${ }^{2}$ and Prashant V. Kamat ${ }^{1,2,3^{*}}$
}

Radiation Laboratory, Department of Chemistry and Biochemistry and Department of Chemical and Biomolecular Engineering University of Notre Dame, Notre Dame, Indiana, 46556, United States

*Corresponding author: pkamat@nd.edu

${ }^{1}$ Radiation Laboratory, University of Notre Dame, Notre Dame, Indiana, 46556, United States

${ }^{2}$ Department of Chemistry and Biochemistry, University of Notre Dame

${ }^{3}$ Department of Chemical and Biomolecular Engineering, University of Notre Dame 


\section{Experimental Section}

\section{Preparation of perovskite film on glass}

Square shaped micro-cover glasses (glass, $22 \times 22 \mathrm{~mm}$, VWR) or $25 \mathrm{~mm}$ diameter round shape micro-cover glasses (1943-10025, Vetrini Coprioggetto) were used for substrate. The cover glasses were washed in soap, acetone and ethanol for 20 min each in sonicator. The washed glasses were dried $12 \mathrm{hrs}$ in oven at $120^{\circ} \mathrm{C}$.

In glove box (< 10 ppm $\left.\mathrm{H}_{2} \mathrm{O}\right), 0.3 \mathrm{M}$ of $\mathrm{CH}_{3} \mathrm{NH}_{3} \mathrm{X}\left(\mathrm{MAX}, \mathrm{CH}_{3} \mathrm{NH}_{3} \mathrm{Br}\right.$ : PN301000, Dyesol / $\mathrm{CH}_{3} \mathrm{NH}_{3}$ I: PN101000, Dyesol) and 0.3 M PbX 2 (PbBr $2:$ A19406, 98\%, Alfa Aesar / Pbl 2 : A11A026, 99.9985\%, Alfa Aesar) with different $\mathrm{Br}: \mathrm{I}$ ratio (0.9 M : $0 \mathrm{M}, 0.45 \mathrm{M}: 0.45 \mathrm{M}, 0 \mathrm{M}: 0.9 \mathrm{M}$ for $\mathrm{Br}$ only, $1: 1$, I only, respectively) were dissolved in anhydrous $N, N$-dimethylformamide (DMF, 227056, 99.8\%, Sigma-Aldrich). The all precursor solutions were filtered through inorganic membrane filter (0.2 $\mu \mathrm{m}$ pore size, G8549141, Whatman). The precursor solutions were spincoated on the cover glass substrate at $5500 \mathrm{rpm}$ for $30 \mathrm{~s}$ (1000 rpm/s ramp rate). To protect the perovskite layer against to ambient air, poly-methyl methacrylate (PMMA, 43982, Alfa Aesar) solution was spun on top of perovskite layer (2000 rpm for $30 \mathrm{~s}, 1000 \mathrm{rpm} / \mathrm{s}$ ramp rate). The PMMA was dissolved in anhydrous chlorobenzene (284513, 99.8 \%, Sigma-Aldrich) with 10 $\mathrm{mg} / \mathrm{ml}$ concentration. To form perovskite structure, the PMMA covered perovskite films were placed on hot place at $100^{\circ} \mathrm{C}$ for $5 \mathrm{~min}$.

\section{Characterizations}

Steady state UV-Vis. absorption spectra were carried out Cary 50 Bio spectrophotometer (Varian).405 nm continuous-wave (CW) $180 \mathrm{~mW}$ laser was on home-built optic system. The CW laser was irradiated to the perovskite film with different intensities through different neutral density filters. While the absorption measurement carried out, $440 \mathrm{~nm}$ long pass filter was utilized in front of detector to cut the CW laser irradiation to the spectrophotometer. Emission measurements were performed in a home build microscope. A405 nm CW laser [Coherent, Obis] was focused onto samples using a high numericalaperture objective (0.75 NA, Nikon). Emissionwas collected with the same objective, a 500 nmlong pass filter was used to reject the $405 \mathrm{~nm}$ laser. Next the emission was directed to a fiber-based spectrometer (Ocean Optics 2000) orsingle photon counting avalanchephotodiode (PerkinElmer, SPCM AQR-14).Time- 
resolved femtosecond transient absorption spectra were measuredwith Helios software (Ultrafast Systems). Pulsed laser was generated through Clark MXR CPA-2010 (130 fs FWHM, 1 $\mu \mathrm{J} /$ pulse) with $1 \mathrm{kHz}$ repetition rate. $95 \%$ of $775 \mathrm{~nm}$ fundamental is doubled to $387 \mathrm{~nm}$ to use pump beam. $5 \%$ of the fundamental was passed to $\mathrm{CaF}_{2}$ crystal and turned to white light as probe beam.Additional $405 \mathrm{~nm} \mathrm{CW} 180 \mathrm{~mW}$ laserwas used to excite probe region. Intensity of the additional CW laser irradiation was controlled through different neutral density filters. With or without the CW laser irradiation, pump and probe beam with time zero $1.5 \mathrm{~ns}$ time delay were incident on the mixed halide perovskite filmsin evacuated cell.To monitor change of $\Delta \mathrm{A}$ under CW laser irradiation, the transient absorption spectra were recorded every $1 \mathrm{~s}$ with 5 ps pump-probe delay without CW laser irradiation first. Then the $\mathrm{CW}$ laser irradiation started while recording the spectra.Atomic Force Microscope (Dimension Icon ${ }^{\circledR}$, Bruker) with the NanoScope $\mathrm{V}$ controller was used for the conductive AFM measurements, employing Pt/Ir coated Si tips (PF TUNA) with a quoted force constant of $0.4 \mathrm{~N} / \mathrm{m}$. The deflection setpoint was kept at $56.00 \mathrm{~nm}$ to both ensure proper contact with the surface damage to a minimum. The samples were imaged both at a positive DC bias of $+0.5 \mathrm{~V}$. All measurements were performed inside a $\mathrm{N}_{2}$-filled glovebox. 
Table S1. The emission rate constants following the irradiation with $405 \mathrm{~nm} \mathrm{CW}$ laser at different intensities. Initial emission decay of mixed halide film at $655 \mathrm{~nm}$ and growth of emission in the I-rich $(755 \mathrm{~nm})$ and $\mathrm{Br}$-rich $(530 \mathrm{~nm})$ regions were measured from different spot or different films. The average value from multiple measurements are given.

\begin{tabular}{|c|c|c|c|}
\hline \multirow{2}{*}{$\begin{array}{c}\text { Power density } \\
\left(\mathrm{mW} / \mathrm{cm}^{2}\right)\end{array}$} & \multicolumn{3}{|c|}{ Rate constant $\left(\mathrm{s}^{-1}\right)$} \\
\cline { 2 - 4 } & Initial & Br-rich & I-rich \\
\hline 200 & $0.43 \pm 0.01$ & $0.09 \pm 0.03$ & $0.09 \pm 0.02$ \\
\hline 636 & $2.18 \pm 0.03$ & $0.13 \pm 0.02$ & $0.11 \pm 0.01$ \\
\hline 1650 & $6.63 \pm 1.78$ & $0.21 \pm 0.18$ & $0.24 \pm 0.17$ \\
\hline
\end{tabular}

Table S2. Exponential growth or decay fitting parameters for change of $\Delta$ Ain Figure 4B.

\begin{tabular}{|c|c|c|c|c|c|c|}
\hline & Equation & $t(s)$ & $\begin{array}{c}\text { Rate constant } \\
\left(s^{-1}\right)(=1 / t)\end{array}$ & $A$ & $y_{0}$ & $r^{2}$ \\
\hline $640 \mathrm{~nm}$ & $y=y_{0}+A^{*} e^{(-x / t)}$ & 3.03 & 0.331 & $-2.65 \times 10^{-2}$ & $-2.01 \times 10^{-3}$ & 0.986 \\
\hline $710 \mathrm{~nm}$ & $y=y_{0}+A^{*} \mathrm{e}^{(-x / t)}$ & 3.05 & 0.328 & $6.30 \times 10^{-3}$ & $-6.49 \times 10^{-3}$ & 0.911 \\
\hline
\end{tabular}



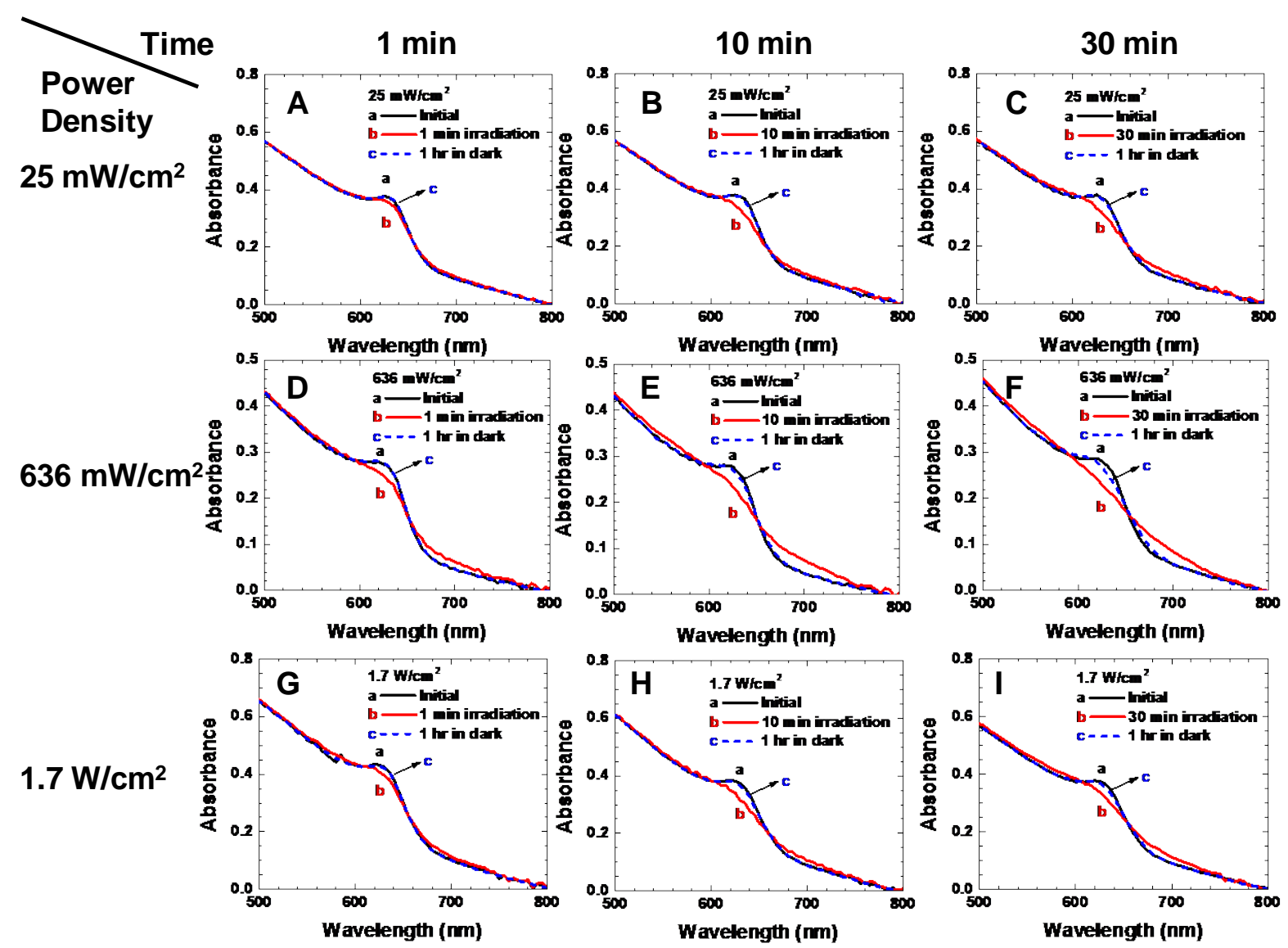

Figure S1. UV-Vis. absorption spectra of $\mathrm{CH}_{3} \mathrm{NH}_{3} \mathrm{PbBr}_{1.3} \mathrm{l}_{1.7}$ filmwith different power densities or time of laser irradiation(405 nm CW laser). (a) Absorption spectra were recorded initially, (b) after laser irradiation, (c) and after storing the film $1 \mathrm{hr}$ in dark conditions.
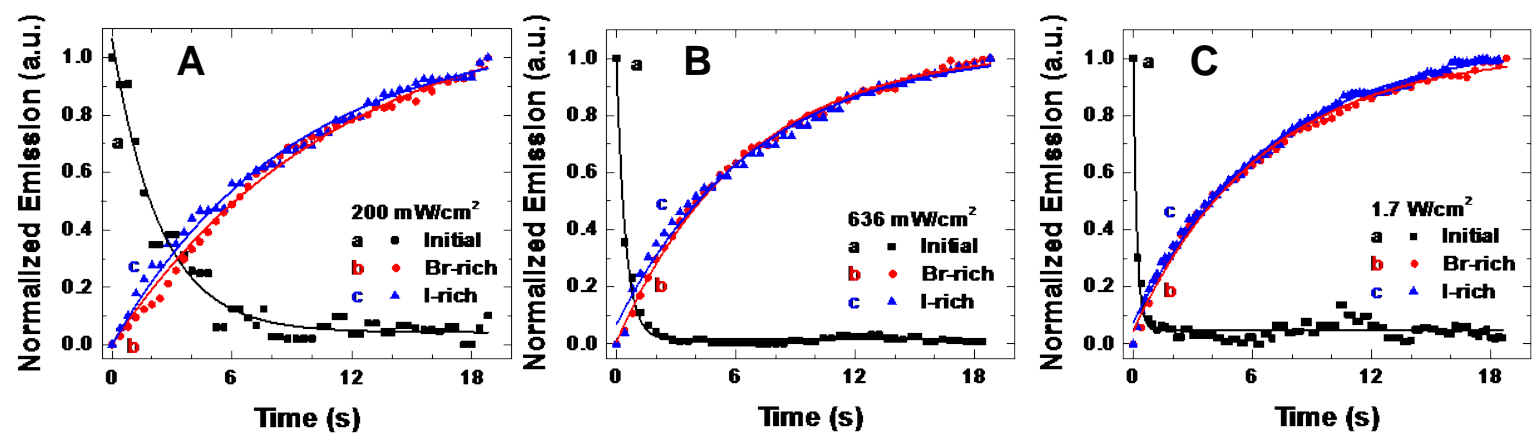
Figure S2. The emission decay of mixed halide film at $655 \mathrm{~nm}$ and growth of emission in the I-rich (755 $\mathrm{nm}$ ) and Br-rich (530 nm) regions following the irradiation with $405 \mathrm{~nm}$ CW laser at different intensities (A: $200 \mathrm{~mW} / \mathrm{cm}^{2}, \mathrm{~B}: 636 \mathrm{~mW} / \mathrm{cm}^{2}, \mathrm{C}: 1.7 \mathrm{~W} / \mathrm{cm}^{2}$ ).

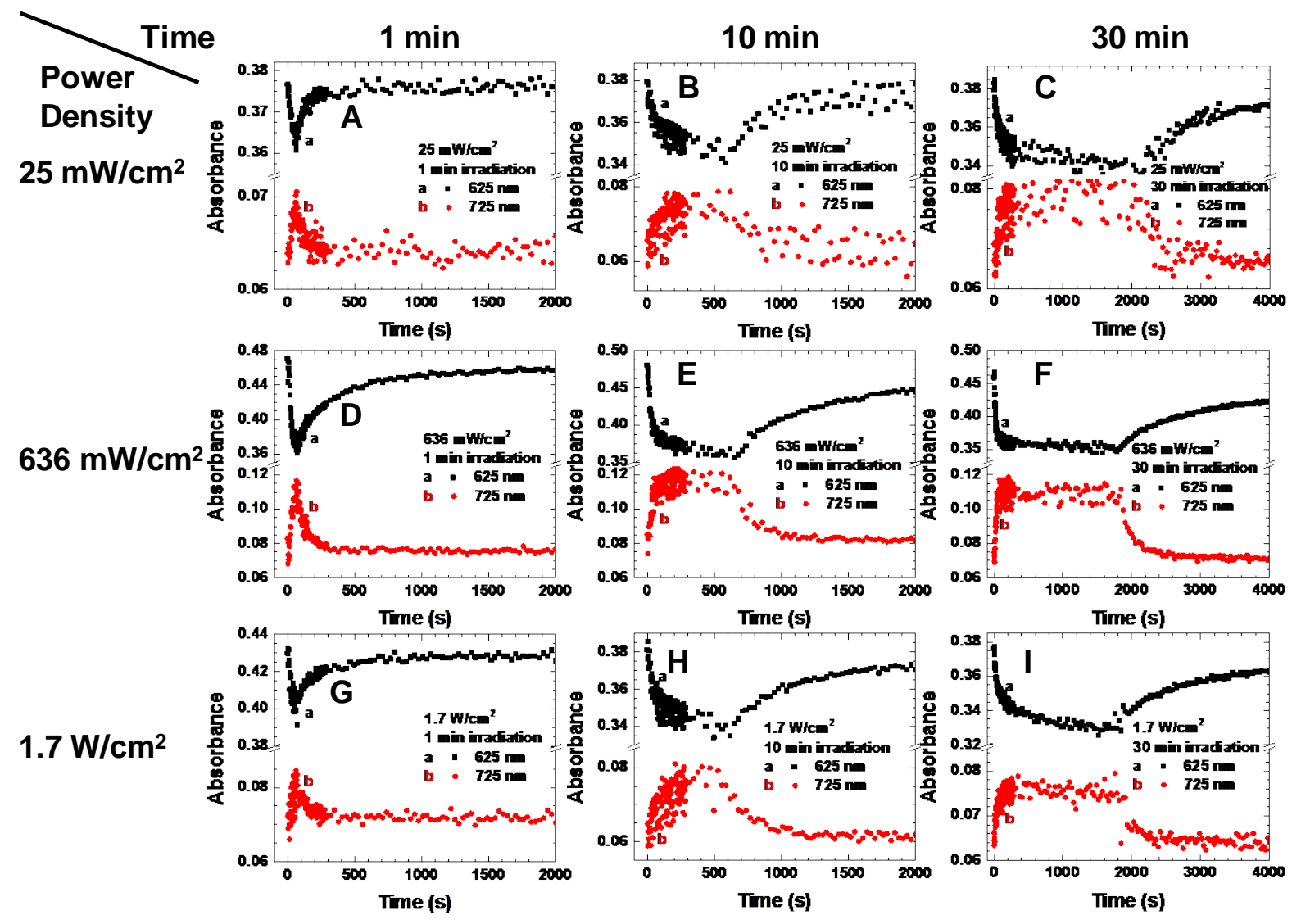

Figure S3. Time evolution of the absorption spectra at(a) $625 \mathrm{~nm}$ and at (b) $725 \mathrm{~nm}$ with different power densities or time of laser irradiation( $405 \mathrm{~nm} \mathrm{CW}$ laser) and after irradiation.

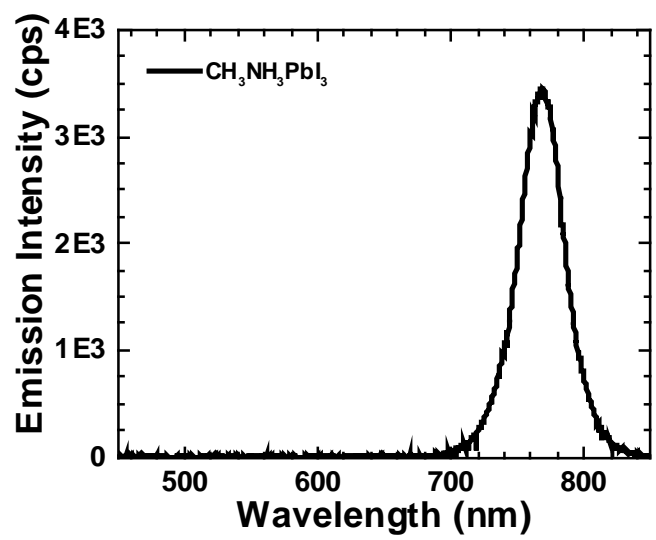


Figure S4. Emission spectrum of $\mathrm{CH}_{3} \mathrm{NH}_{3} \mathrm{Pbl}_{3}$ film using excitation at $405 \mathrm{~nm}$.

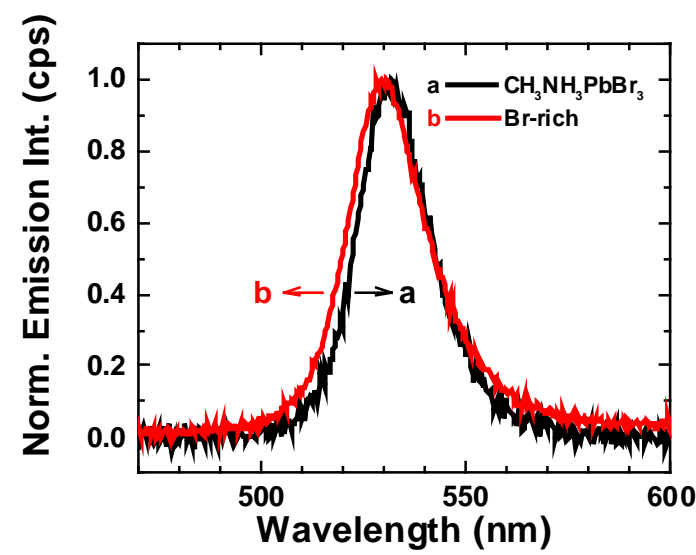

Figure S5. Normalized emission spectra (a) $\mathrm{CH}_{3} \mathrm{NH}_{3} \mathrm{PbBr}_{3}$ film, (b) emission at $530 \mathrm{~nm}$ from $\mathrm{CH}_{3} \mathrm{NH}_{3} \mathrm{PbBr}_{1.3} \mathrm{l}_{1.7}$ film after $1 \mathrm{~min}$ irradiation of $405 \mathrm{~nm} \mathrm{CW}$ laser with $200 \mathrm{~mW} / \mathrm{cm}^{2}$ power density.

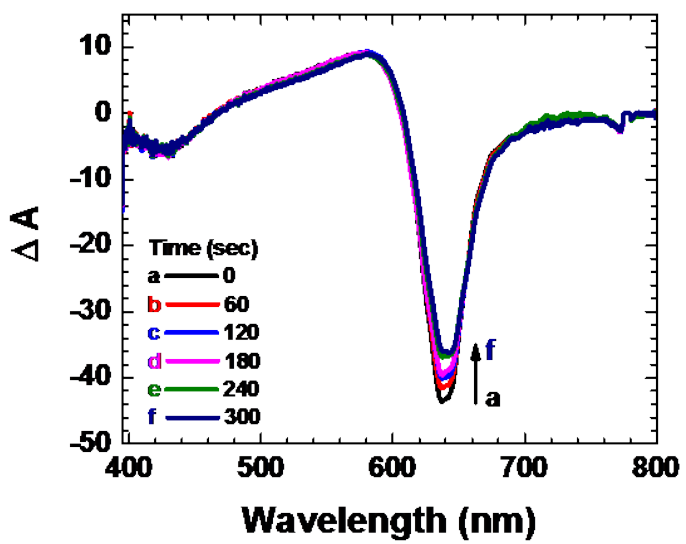

Figure S6. Femtosecond transient absorption spectra of $\left.\mathrm{CH}_{3} \mathrm{NH}_{3} \mathrm{PbBr}_{1.3}\right|_{1.7}$ film with 5 ps pump-probe delay $\left(4 \mu \mathrm{J} / \mathrm{cm}^{2}\right.$ as pump power density) without $405 \mathrm{nmCW}$ laser irradiation. 


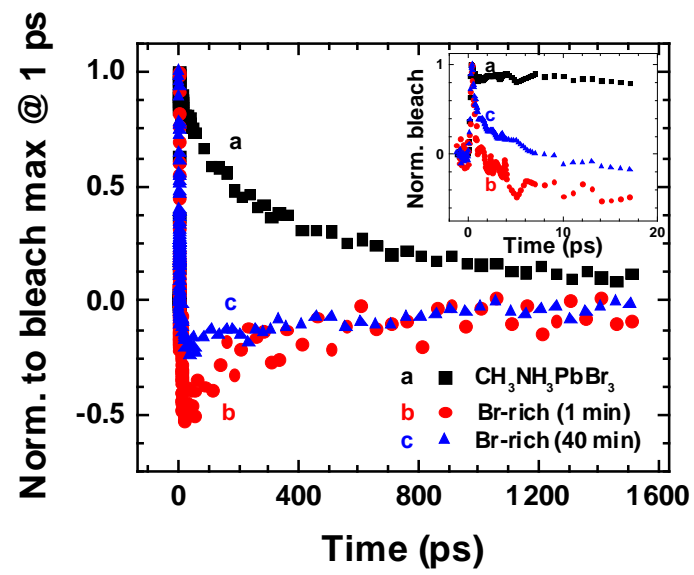

Figure S7. Transient recovery of bleaches from (a) $\mathrm{CH}_{3} \mathrm{NH}_{3} \mathrm{PbBr}_{3}, \mathrm{Br}$-rich (b: 1 min CW laser irradiation c: 40 min CW laser irradiation). Inset shows early pump-probe delay time of the transient recovery to 20 ps.
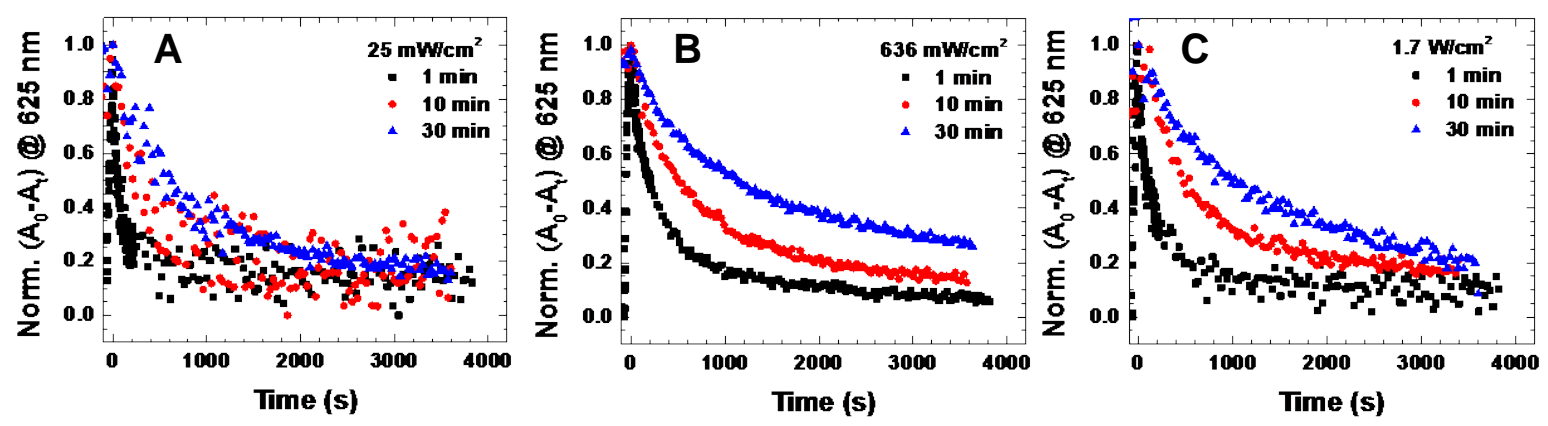

Figure S8. Dependence of absorption recovery of $\mathrm{CH}_{3} \mathrm{NH}_{3} \mathrm{PbBr}_{1.3} \mathrm{I}_{1.7}$ film on the different irradiation time and intensities (A: $25 \mathrm{~mW} / \mathrm{cm}^{2}, \mathrm{~B}: 636 \mathrm{~mW} / \mathrm{cm}^{2}, \mathrm{C}: 1.7 \mathrm{~W} / \mathrm{cm}^{2}$ ). 